\title{
POSSÍVEIS SOLUÇÕES PARA ELEVAR O DESEMPENHO EMPREENDEDOR DE UMA CIDADE: UM ESTUDO PRELIMINAR SOBRE A OPINIÃO DOS ATORES DO ECOSSISTEMA EMPREENDEDOR DA CIDADE DE PORTO ALEGRE/RS
}

Claudio Farias ${ }^{1}$

Duilio Castro Miles ${ }^{1}$

${ }^{1}$ Campus Porto Alegre / Instituto Federal do Rio Grande do Sul 


\section{POSSÍVEIS SOLUÇÕES PARA ELEVAR O DESEMPENHO EMPREENDEDOR DE UMA CIDADE: UM ESTUDO PRELIMINAR SOBRE A OPINIÃO DOS ATORES DO ECOSSISTEMA EMPREENDEDOR DA CIDADE DE PORTO ALEGRE/RS.}

Resumo: O presente artigo pretende realizar uma reflexão a cerca das possibilidades de elevar o desempenho da cidade de Porto Alegre, capital do Rio Grande do Sul. O objetivo principal foi levantar, a partir da análise das opiniões dos responsáveis das principais organizações que compõem o ecossistema empreendedor de Porto Alegre, as iniciativas que melhorem o desempenho empreendedor da cidade. Sob o ponto de vista metodológico, a pesquisa tem um caráter exploratório-descritivo, com uma abordagem quanti-qualitativa, fazendo uso de técnicas de coleta de dados baseadas em entrevistas e análise documental. Entrevistou-se um total de dezessete representantes das diferentes organizações deste ecossistema. Entre as principais iniciativas para melhorar o desempenho do ecossistema foram mencionados: Integrar esforços de universidades e centro de pesquisa para estimular a criação de novas empresas; Avançar na redução do tempo do processo de abertura de novos empreendimentos, por meio de uma maior informatização desses processos.

Palavras-chave: Desempenho empreendedor. Ecossistema empreendedor. Cidades empreendedoras

\section{Introdução}

A temática do empreendedorismo, que até bem pouco tempo, estava circunscrita no âmbito das firmas ou dos talentos individuais dos seus protagonistas, vem ganhando novas roupagens nos últimos anos. O termo "empreendedorismo", segundo muitos autores, surge como uma forma genérica de explicar a dinâmica do sistema capitalista, originalmente cunhado pelo economista Joseph Schumpeter (LUNDVALL, 1992; PORTER, 1998; ARRUDA et al, 2013;). Ao longo dos tempos, a literatura parece ter migrado para um campo mais intimista e psicológico, dando mais valor ao "agente empreendedor" do que ao "processo empreendedor". Mais recentemente, nos últimos dez anos, um certo movimento tem se consolidado no sentido de propor um conjunto de estruturas explicativas ao surgimento e consolidação de ambientes socialmente construídos para dar suporte ao empreendedorismo - são os chamados Ecossistemas Empreendedores (ISENBERG, 2010; STAM, 2015; MASON; BROWN, 2013).

Um dos autores proeminentes no desenvolvimento do conceito de "Ecossistemas Empreendedores" é Daniel Isenberg, professor da Babson College. Isenberg define um ecossistema de empreendedorismo como "um conjunto de instituições em rede [...] com o objetivo de ajudar o empreendedor a percorrer todas as etapas do processo de desenvolvimento de novos empreendimentos" (ISENBERG, 2010). Ele caracteriza ainda um ecossistema empreendedor em quatro partes: (1) consiste de seis pilares/domínios (política, finanças, cultura, apoios, capital humano, mercados); (2) Cada ecossistema empreendedor é único, não podendo ser replicado; (3) A especificação de causas genéricas do ecossistema empresarial tem um valor prático limitado; (4) Os ecossistemas empreendedores tornam-se (relativamente) autossustentáveis assim que os seis pilares/domínios são suficientemente fortes (ISENBERG, 2010).

Com base nesse conceito de Ecossistemas Empreendedores, e em outros conceitos anteriormente desenvolvidos, como o de Sistemas Nacionais de Inovação, nos últimos anos, uma série

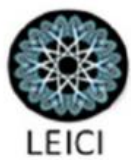


de organismos internacionais vêm apresentando metodologias distintas de análise e comparação desses ambientes empresariais. O Banco Mundial realiza, desde 2004, uma pesquisa cross-country, que visa analisar as diferentes as regulamentações que as empresas devem cumprir, ao longo de sua existência, para atuarem em seus mercados locais. Tais resultados são divulgados anualmente através do Relatório Doing Business. Entre as regulamentações analisadas, estão desde o processo de abertura das empresas, as formas de operações, os acessos ao comércio internacional, a carga tributária, entre outros indicadores. Após a análise, o Relatório classifica os países quanto à facilidade de se fazer negócios. No ano de 2004, o Relatório apontou que no Brasil eram necessários 152 dias para completar o processo de abertura de um novo negócio, enquanto que a média na Austrália era de apenas dois dias. O Relatório Doing Business, de 2015, apontou, ainda, que um processo de falência no Brasil leva, em média, dez anos para ser concluído.

Outro importante estudo, desenvolvido pelo Grupo Endeavor, é o Índice de Cidades Empreendedoras (ICE). No Brasil, tal Índice é aferido desde 2014, de forma anual. No ICE 2016, por exemplo, foram analisadas 32 cidades brasileiras, de 22 estados. Com exceção da região Norte, onde são analisadas apenas Belém e Manaus, todos os estados das demais regiões foram representados ao menos por suas capitais. Além da grande abrangência geográfica, juntas essas cidades representam também cerca de $40 \%$ do PIB nacional. O ICE avalia o desempenho de cada cidade, nos seis pilares que constituem um ecossistema empreendedor: ambiente regulatório, infraestrutura, mercado, acesso a capital, inovação e capital humano ${ }^{1}$.

$\mathrm{O}$ presente artigo pretende realizar uma reflexão a cerca das possibilidades de elevar o desempenho da cidade de Porto Alegre, capital do Rio Grande do Sul (Brasil) ${ }^{2}$. Porto Alegre, segundo o ICE 2016, ocupa a $7^{a}$ posição entre as 32 cidades brasileiras analisadas. Porém, ao se observar o resultado em cada pilar do ecossistema verifica-se que em determinados pontos, Porto Alegre está entre as últimas colocadas, como é o caso do ambiente regulatório. O objetivo principal do presente trabalho é levantar, a partir da análise das opiniões de representantes das principais organizações que compõem o ecossistema empreendedor de Porto Alegre, sugestões para elevar os índices da cidade.

O presente artigo pretende apresentar alternativas viáveis, a partir do olhar dos agentes participantes no ecossistema empreendedor de Porto Alegre, para melhoria do desempenho do mesmo. Pretende-se, com isso, auxiliar a criação de um planejamento de ações objetivas, que visem a obtenção de melhores resultados nos próximos levantamentos do ICE. Igualmente, pretende-se verificar as possibilidades de ações conjuntas entre os diversos agentes, no sentido de promover um ambiente sistêmico "pró-inovação". Preliminarmente, observa-se que algumas iniciativas já começam a ser tomadas, sobretudo pela ação conjunta entre o poder público e organizações de apoio empresarial, no sentido de melhorar o desempenho de Porto Alegre, em especial no que tange à redução da burocracia para abertura e fechamento de empresas.

Uma vez que os ecossistemas empreendedores contêm componentes múltiplos e interligados (e o caso de Porto Alegre é um bom exemplo), a construção de tais ecossistemas implica uma abordagem equilibrada e coordenada - e neste ponto entende-se a importância do presente trabalho: possibilitar aos atores a análise dos pilares constitutivos do ecossistema, possibilitando um olhar crítico sobre esses, bem como a sugestão de mecanismos de melhoria de seu desempenho.

${ }^{1}$ O ICE inclui um sétimo pilar (cultura empreendedora), em associação com os Relatórios produzidos pela Global Entrepreneurship Network (GEN).

2 Porto Alegre possui uma área total de 496,682 km², com uma população estimada de 1.476 .867 habitantes (2015); PIB (2013): PIB per capita (2013): US\$ 12.215,00 (71 a posição no Rio Grande do Sul e $350^{a}$ no Brasil), Maior Índice de Desenvolvimento Humano (2010) no estado: 0,805 (alto). Participação por setores econômicos: Agropecuária: 0,05\%, Indústria: $15,89 \%$. Serviços: $84,06 \%$.

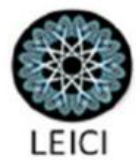


Ao abordar esses obstáculos, o que se pretende é desenvolver as condições de uma política pública e de um quadro institucional propício ao empreendedorismo. No entanto, ainda que as políticas públicas e as instituições sejam incluídas como fatores-chave em diferentes modelos de ecossistema empresarial, na prática é frequentemente o elemento mais negligenciado (NADGRODKIEWICZ, 2013). A razão é simples: embora seja fácil prestar louvor à necessidade de políticas que apoiem o empreendedorismo, é muito mais difícil alcançá-las, sobretudo considerando a inconstância e falta de continuidade das políticas públicas, marcas do modelo brasileiro de gestão pública.

\section{2 - FUNDAMENTAÇÃO TEÓRICA}

\subsection{Conceito de Ecossistema Empreendedor}

Os primeiros registros do conceito de ecossistema empreendedor estão associados ao trabalho de James F. Moore (2006). Para ele, o ecossistema é uma metáfora para representar a forma como os diversos atores articulam-se entre si para produzir valor.

O autor baseou-se nos conceitos de coevolução, do antropólogo Gregory Bateson, que defende a existência de uma interdependência entre a evolução das espécies em ciclos intermináveis e recíprocos; também, baseou-se no conceito do biólogo Stephen Jay Gould, de que os sistemas naturais, muitas vezes, entram em colapso devido às mudanças em condições radicais, dando lugar a outros atores e novos ecossistemas. Moore (2006) sugere que é possível estender estes conceitos para ecossistemas de negócios.

Ron Adner e Rahul Kapoor (2010) foram autores que contribuíram na junção destes dois conceitos. Para eles, os ecossistemas são uma forma de explicitar os vínculos de interdependência dos atores para a criação e captura de valor.

Do ponto de vista teórico, o conceito de um ecossistema empreendedor trata da interação existente entre um conjunto de atores institucionais e individuais, com vistas a fomentar o espírito empresarial, a inovação e o crescimento das Pequenas e Médias Empresas (PME's). Este conceito tornou-se mais proeminente em 2010, por meio do professor Daniel Isenberg, da Babson College, através do seu artigo publicado na Harvard Business Review (ISENBERG, 2010). Para Isenberg, os componentes básicos de um ecossistema empreendedor estão expressos pelos domínios que se interrelacionam, formando um Ecossistema Empreendedor (Figura 1). 
FIGURA 1 - Domínios do Ecossistema Empreendedor

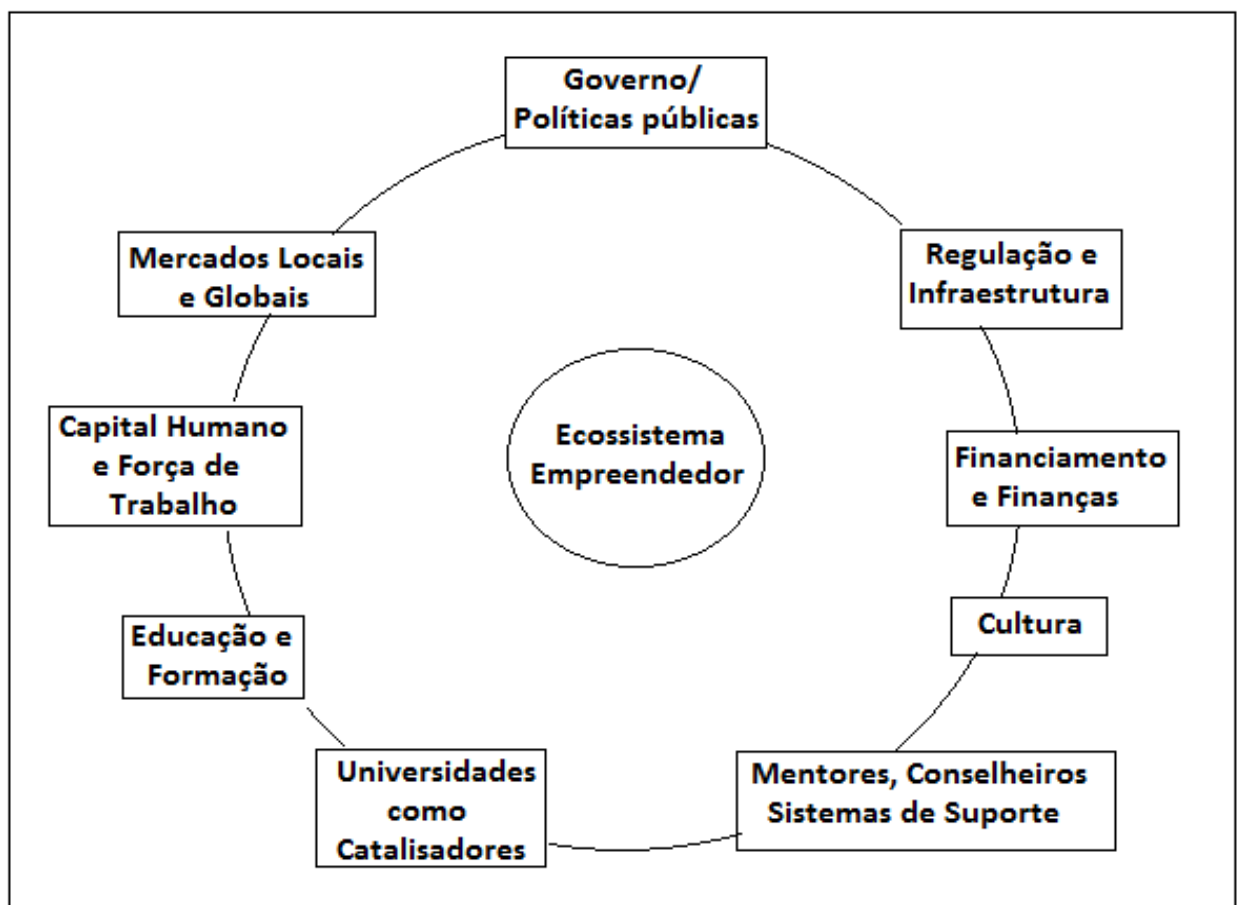

Fonte: adaptado de ISENBERG (2010).

No entanto, o conceito tem os seus antecedentes em trabalhos anteriores que se referiam a agrupamentos regionais de empresas de diversos setores e de outras entidades (PORTER, 1998; KRUGMAN, 1991), condições para a promoção do empreendedorismo tecnológico (VENKATRAMAN, 2004) bem como, a criação de Sistemas Nacionais de Inovação.

Para Cohen (2006), ecossistema de empreendedorismo corresponde a:

[...] um conjunto diversificado de atores interdependentes que, dentro de uma região geográfica, influenciam na formação e eventual trajetória de todo o grupo de atores e potencialmente na economia como um todo. Os ecossistemas empreendedores evoluem a partir de um conjunto de componentes interdependentes que interagem para gerar a criação de novos negócios ao longo do tempo. (COHEN; 2006, p. 2-3).

Isenberg (2010) apresenta a existência de nove condições para o desenvolvimento de um ecossistema empreendedor, descritos a seguir:

1) Ainda que o Vale do Silício seja um ecossistema empreendedor bem-sucedido é exclusivo da sua região e é improvável ser replicado em outras áreas;

2) Formar o ecossistema em torno das condições locais, ou seja, olhar para as indústrias de base local com potencial de crescimento e a partir daí construir os alicerces do ecossistema empreendedor;

3) Envolver o setor privado desde o início, ou seja, o processo deve ser liderado pelo setor privado e o papel do governo é o de facilitador;

4) Dar especial atenção ao fomento das empresas com potencial de crescimento e com a capacidade de inovação e seu engajamento no mercado mundial;

5) Usar o caso ou os casos de sucesso para estimular e motivar as outras empresas; 
6) Enfrentar os desafios, evitando que a atividade empresarial seja sufocada por uma cultura avessa ao risco ou conservadora, e apostando em programas de comunicação e educação;

7) As empresas orientadas para o crescimento não devem ser inundadas com 'dinheiro fácil' através de subvenções ou fluxos de capital de risco. As empresas devem ser rentáveis e sustentáveis, aplicando uma gestão financeira;

8) Não investir apenas em clusters tecnológicos, pois deve-se ajudar os clusters a crescerem organicamente. Por vezes o entusiasmo do governo na construção de clusters industriais precisa ser temperado por uma percepção permitindo que estes surjam de forma orgânica através de indústrias existentes e não da tentativa de "escolher vencedores" ou através da construção de parques de ciência e tecnologia);

9) Reforma dos quadros jurídicos, burocráticos e regulamentares. O governo tem um papel fundamental para as empresas na regulação de um conjunto de normas e regulamentos que podem facilitar o processo empreendedor e diminuir a burocracia (ISENBERG, 2010, pp. 3-10).

Desta forma, os ecossistemas de empreendedorismo são ambientes complexos, de caráter evolutivo, holístico e dinâmico. Os mesmos também são particulares a determinada região - como uma cidade, por exemplo. Até mesmo diferentes distritos de uma cidade podem ter ecossistemas de empreendedorismo com configurações distintas entre si (ISENBERG, 2010, p. 10).

A constituição de um ecossistema empreendedor é bem diversa e um ator pode estar em mais de um ecossistema ao mesmo tempo. Pode-se dividir a formatação de um ecossistema empreendedor em seis conjuntos: redes informais, redes formais, o governo, apoios profissionais de serviços, serviços de acesso a capital e profissionais qualificados.

O propósito principal em estar participando de um ambiente empresarial sistêmico é primeiramente reconhecer limitações e compreender quais são os agentes que podem mitigar potenciais riscos do negócio nascente. Dessa forma, um dos papéis fundamentais dos ecossistemas empreendedores é dividir incertezas do ambiente para, assim, diminuir as chances de fracasso dos empreendimentos. A abordagem ecossistêmica possibilita ampliar o campo de visão empresarial e a formação de uma atitude de colaboração voltada à construção de valor para os clientes e para a própria empresa.

Cabe ressaltar que não há uma fórmula ou modelo específico para criação ou desenvolvimento de ecossistemas empreendedores, pois existem aspectos particulares para cada tipo de arranjo, que variam de acordo com a região na qual os agentes estão inseridos, inerentes à dinâmica interna de cada um deles. Amaral Filho (2002) afirma que nos casos exitosos de organização coletiva de micro e pequenas empresas verificou-se a presença de quatro elementos estruturantes. Estes elementos, de acordo com o autor, são: capital social, estratégias coletivas de organização da produção, estratégias coletivas de mercado e articulação político-institucional.

Ao mencionar o capital social ${ }^{3}$, o autor se refere a um fator intangível por natureza, representando um acúmulo de compromissos sociais consolidados pelas interações sociais em uma determinada localidade. Por sua vez, este capital social serve de apoio a outro componente, conhecido como estratégia coletiva de organização da produção. Esta estratégia se relaciona com as decisões coordenadas, entre os produtores, no que se refere a quem vai produzir, o que produzir e como produzir. E é por meio desta estratégia que a aglomeração das pequenas empresas determina seu poder em relação às grandes empresas, por exemplo, através da equivalência da vantagem em relação à escala da compra dos insumos, do uso de máquinas e equipamentos, da produção em geral etc. De

${ }^{3}$ Para maior entendimento, ver Albagli e Maciel (2003); Portes (2000); Costa e Costa (2005).

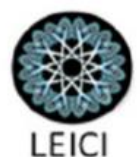


igual modo, é por meio da estratégia coletiva de organização da produção que se revela e se processa a aprendizagem coletiva, fonte das inovações e da competitividade.

O terceiro elemento, conforme Amaral Filho (2002) está direcionado à estratégia coletiva de mercado. Esta também está voltada para as ações coordenadas e convergentes entre os produtores. Sem uma estratégia comum entre os produtores, as pequenas empresas veriam reduzidos os ganhos conseguidos nas economias de escala, alcançados nas esferas da compra dos insumos e na realização da produção.

O último ponto citado por Amaral Filho (2002) está voltado para a articulação políticoinstitucional, também decorrida do capital social. Este é o instrumento pelo qual os empreendimentos se articulam com instituições públicas e privadas, responsáveis pelas políticas públicas, e com as organizações privadas de apoio às empresas. Amaral Filho aponta que "as evidências revelam que, quanto mais capital social acumulado dentro de num determinado núcleo ou aglomeração de empresas, melhor e mais eficiente será a articulação com as organizações e instituições" (2002: 580).

Outro conceito, correlato ao constructo dos ecossistemas empreendedores são os sistema produtivos de inovação. Cassiolato e Szapiro (2002) propõem que os sistemas produtivos e inovativos locais que são "aqueles arranjos produtivos em que interdependência, articulação e vínculos consistentes resultam em interação, cooperação e aprendizagem, com potencial de gerar o incremento da capacidade inovativa endógena, da competitividade e do desenvolvimento local" (CASSIOLATO; SZAPIRO, 2002: 17).

Os pesquisadores da REDESIST definem os sistemas produtivos e inovativos locais como "[...] conjuntos de agentes econômicos, políticos e sociais, localizados em um mesmo território, desenvolvendo atividades econômicas correlatas e que apresentam vínculos expressivos de produção, interação, cooperação e aprendizagem”. Portanto,

[...] geralmente incluem empresas - produtoras de bens e serviços finais, fornecedoras de equipamentos e outros insumos, prestadoras de serviços, comercializadoras, clientes, etc., cooperativas, associações e representações - e demais organizações voltadas à formação e treinamento de recursos humanos, informação, pesquisa, desenvolvimento e engenharia, promoção e financiamento (REDESIST, 2005: 1).

Pode-se dizer que o embrião da ideia de sistemas e arranjos localizados é o conceito de sistema nacional de inovação. Desenvolvido por Lundvall (1992) e Freeman (1995), tal conceito tem por base a consideração de que os atores econômicos e sociais e as relações entre eles determinam em grande medida a capacidade de aprendizado de um país e, portanto, a capacidade de inovar e de se adaptar às mudanças do ambiente. Desempenhos nacionais, relativos à inovação, derivam de uma confluência social e institucional, particulares entre si e de características histórico-culturais específicas (LASTRES et al, 1999). Esse conceito já vem sendo discutido em níveis locais e regionais.

Os sistemas nacionais, regionais ou locais de inovação podem ser tratados, dessa forma, como uma rede de instituições dos setores público (instituições de pesquisa e universidades, agências governamentais, empresas públicas e estatais, entre outros) e privado (como empresas, associações empresariais, sindicatos, organizações não-governamentais etc.) cujas atividades e interações geram, adotam, importam, modificam e difundem novas tecnologias, sendo a inovação e o aprendizado aspectos cruciais para o seu desempenho exitoso (FARIAS, 2010).

Percebe-se que a ótica dos sistemas de inovação e de ecossistemas empreendedores são complementares, e se apresentam como uma importante unidade de análise, captando a relação que se estabelece entre os agentes pertencentes a um território específico, desenvolvendo nesse local, um espaço de aprendizagem particular. Dessa forma, cabe destacar a importância do aprendizado interativo entre os agentes, pondo em evidência, para além das trocas de bens e insumos entre as

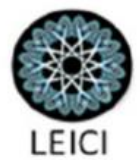


empresas, a importância das trocas de informação e conhecimento, não apenas entre as firmas, mas destas com uma gama de organizações, muitas delas criadas para proporcionar esse fim: uma maior interação entre agentes em um território definido.

\section{3)PROCEDIMENTOS E MÉTODOS}

Sob o ponto de vista metodológico, a pesquisa teve um caráter exploratório-descritivo, com uma abordagem quanti-qualitativa, fazendo uso de técnicas de coleta de dados baseadas em entrevistas e análise documental. Inicialmente, tendo por referência o ICE 2016, elaborou-se um roteiro de entrevistas semiestruturado. O estudo ouviu algumas das principais organizações pertencentes ao ecossistema, ligadas a quatro estruturas-chave: órgãos governamentais; instituições de ensino e pesquisa; organizações de apoio empresarial; empresários e profissionais liberais. Entrevistou-se um total de dezessete pessoas, representando as organizações supramencionadas, conforme o quadro abaixo.

Quadro 1 - Distribuição das entrevistas, conforme estruturas-chave

\begin{tabular}{|l|c|}
\hline \multicolumn{1}{|c|}{ Estruturas-chaves } & Número de entrevistados \\
\hline Órgão governamental & 4 \\
\hline Instituição de Ensino e Pesquisa & 1 \\
\hline Organizações de Apoio Empresarial & 7 \\
\hline Empresários e Profissionais Liberais & 4 \\
\hline Total & 16 \\
\hline
\end{tabular}

Fonte: elaborado pelos autores

Com base em levantamentos bibliográficos e documentais anteriores, foi elaborado um instrumento de coleta de dados, composto de dezoito sentenças, e para cada uma delas, foi solicitada a manifestação dos entrevistados com relação ao seu grau de concordância, medido através de uma escala Likert de cinco pontos $(1=$ discordo totalmente; $5=$ concordo totalmente). As propostas para melhoria do desempenho do ecossistema empreendedor de Porto Alegre foram avaliadas pelos entrevistados, sendo que as varáveis associadas a cada proposta estão presentes no Quadro 2.

Quadro 2 - Propostas para melhoria de ecossistema empreendedor (variáveis)

\begin{tabular}{|l|l|}
\hline \multicolumn{1}{|c|}{ Variável } & \multicolumn{1}{c|}{ Descrição } \\
\hline ISS_lucro & Mudar a base de cálculo da tributação para o lucro \\
\hline ISS_carência & $\begin{array}{l}\text { Reduzir da alíquota do imposto de serviços da base municipal para PME’s } \\
\text { por um período de 3 a 5 anos }\end{array}$ \\
\hline Redução_tempo & Reduzir do tempo de abertura de novos empreendimentos \\
\hline Ampliar_informatização & Informatizar processos de abertura/encerramento \\
\hline EGoverment & Avançar nos serviços públicos gerenciados pela internet \\
\hline Dívidas_fiscais & Criar mecanismos de recuperação de empresas por dívidas fiscais \\
\hline Novas_potencialidades & $\begin{array}{l}\text { Políticas públicas de incentivo para desenvolver setores econômicos com } \\
\text { potencial }\end{array}$ \\
\hline Instalação_empresas & $\begin{array}{l}\text { Implementar facilidades para atrair empresas nacionais e internacionais na } \\
\text { área tecnológica }\end{array}$ \\
\hline Interação_governo_sociedade & $\begin{array}{l}\text { Promover maior interatividade entre governo-sociedade na busca de } \\
\text { soluções para a gestão pública }\end{array}$ \\
\hline Comércio_Exterior & Incentivar a inserção das PME’s no mercado internacional \\
\hline Educação_Empreendedora & Desenvolver programas de educação empreendedora ao longo do processo \\
\hline
\end{tabular}




\begin{tabular}{|l|l|}
\hline & de ensino formal. \\
\hline Cursos_capacitação & $\begin{array}{l}\text { Realizar parcerias entre o governo e instituições de ensino para } \\
\text { desenvolver a capacidade empreendedora }\end{array}$ \\
\hline Encontro_empreendedores & Aproximar potenciais empreendedores com investidores \\
\hline Campanha_institucional & Promover campanhas para desenvolver o empreendedorismo \\
\hline Microcrédito & Avançar na política de microcrédito para as PME's \\
\hline Integrar_IES & $\begin{array}{l}\text { Integrar os esforços das entidades de suporte para estímulo à criação de } \\
\text { novas empresas }\end{array}$ \\
\hline Compras_públicas & Viabilizar os programas de compras públicas para as PME’s \\
\hline Fundo_Municipal & $\begin{array}{l}\text { Criar Fundo para apoiar as empresas como potencial de desenvolvimento } \\
\text { de negócios inovadores. }\end{array}$ \\
\hline
\end{tabular}

Fonte: elaborado pelos autores

Igualmente, foi apresentado aos entrevistados uma lista com os seis domínios de um ecossistema empreendedor, segundo Isenberg (2010), sendo solicitado que os mesmos classificassem, por ordem de prioridade, os domínios que, segundo suas percepções e experiências, necessitariam de maior intervenção, a fim de que o índice de empreendedorismo de Porto Alegre viesse a ter uma melhor desempenho.

Por fim, os entrevistados tinham um tempo para apresentarem outras medidas, para além daquelas avaliadas, que em suas percepções, poderiam ser adotadas para melhor o desempenho da cidade. Dessa forma, realizou-se tanto uma avaliação tanto quantitativa quanto qualitativa das percepções dos entrevistados.

Em termos de análise dos dados, para a etapa quantitativa, optou-se, por ser um estudo preliminar, por usar as ferramentas da estatística descritiva, a partir de cálculos das médias e distribuições de frequências. Utilizou-se o software de tratamento estatístico SPSS. Para a etapa qualitativa, utilizou-se a análise de conteúdo como ferramenta analítica. Os principais resultados estão presentes na seção seguinte.

\section{4) RESULTADOS}

Inicialmente, cumpre realizar uma breve descrição da amostra dos entrevistados. Dos dezesseis entrevistados, $69 \%$ eram homens e $31 \%$ mulheres. A formação acadêmica mais frequente é a o mestrado e doutorado, citado por $56 \%$ dos entrevistados. Em termos de tempo de experiência/envolvimento com o ecossistema de Porto Alegre, $60 \%$ dos entrevistados mencionaram que participam a mais de 10 anos de atividades ligadas ao desenvolvimento empreendedor da cidade.

Tabela 1 - Média, Moda e Desvio Padrão das respostas

\begin{tabular}{l|c|c|c}
\hline \multicolumn{1}{c|}{ Variável } & Média & Moda & $\begin{array}{c}\text { Desvio } \\
\text { Padrão }\end{array}$ \\
\hline ISS_lucro & 4,29 & 5 & 1,36 \\
\hline ISS_carência & 3,83 & 5 & 1,42 \\
\hline Redução_tempo & 4,53 & 5 & 1,18 \\
\hline Ampliar_informatização & 4,53 & 5 & 1,12 \\
\hline EGoverment & 4,35 & 5 & 1,17 \\
\hline Dívidas_fiscais & 3,76 & 4 & 1,03 \\
\hline Novas_potencialidades & 4,41 & 5 & 1,23 \\
\hline Instalação_empresas & 4,11 & 5 & 1,11 \\
\hline
\end{tabular}




\begin{tabular}{l|l|l|l}
\hline Interação_governo_sociedade & 4,29 & 5 & 1,10 \\
\hline Comércio_Exterior & 3,94 & 5 & 1,20 \\
\hline Educação_Empreendedora & 4,47 & 5 & 1,00 \\
\hline Cursos_capacitação & 4,23 & 5 & 1,09 \\
\hline Encontro_empreendedores & 4,23 & 5 & 1,09 \\
\hline Campanha_institucional & 3,88 & 5 & 1,27 \\
\hline Microcrédito & 4,17 & 5 & 1,27 \\
\hline Integrar_IES & 4,70 & 5 & 0,98 \\
\hline Compras_públicas & 4,29 & 5 & 1,10 \\
\hline Fundo_Municipal & 4,05 & 5 & 1,29 \\
\hline
\end{tabular}

Fonte: dados da pesquisa

A Tabela 1 apresenta um resumo das respostas dos entrevistados. Os entrevistados foram questionados com relação ao grau de concordância, em relação a uma série de medidas que poderiam, em tese, melhorar o desempenho empreendedor de Porto Alegre. De modo surpreendente, o a variável com maior grau de concordância foi a associada a necessidade de uma maior interação entre as instituições de ensino superior e centros de pesquisa $(4,70)$, seguida da adoção de medidas para a redução dos prazos para abertura de empresas $(4,53)$ e a ampliação da informatização dos processos $(4,53)$, bem como a implementação de programa efetivos de educação empreendedora, tendo início no ensino básico e indo até o ensino superior $(4,47)$.

Tais resultados estão em concordância com as pesquisas desenvolvidas pela Endeavor, sobretudo com as avaliações realizadas através da pesquisa do Índice de Cidades Empreendedoras (ICE). A referida pesquisa aponta que as principais fragilidades de Porto Alegre estão associadas aos processos burocráticos de abertura e fechamento de empresas, bem como a ausência de uma cultura empreendedora consolidada. A falta de integração entre as universidades e centros de pesquisa é apontada como a principal medida a ser empreendida para efetivar a melhoria dos índices da cidade. Porto Alegre possui uma gama de excelentes universidades e centros de pesquisa, que se destacam entre as melhores do Brasil. A ausência de integração entre tais instituições, na opinião dos entrevistados, faz surgir barreiras ao desenvolvimento de negócios, sobretudo aqueles ligados a um ambiente tecnológico mais sofisticado.

Importante ressaltar que, no senso comum, as principais medidas debatidas, em especial pela classe empresarial, estão associadas às reduções tributárias. No entanto, para os entrevistados, todas as medidas ligadas às questões tarifárias são entendidas como de menor importância.

Quanto solicitados a elencar os domínios do ecossistema, conforme Isenberg (2010), que deveriam ser priorizados, a fim de melhorar o desempenho empreendedor da cidade, os entrevistados apresentaram as seguintes respostas, resumidas na Tabela 2.

Tabela 2 - Priorização dos Domínios do ecossistema empreendedor de Porto Alegre

\begin{tabular}{|c|c|c|c|c|c|c|}
\hline & $\begin{array}{l}\text { Políticas } \\
\text { Públicas } \\
\end{array}$ & $\begin{array}{c}\text { Mercado } \\
\text { Financeiro } \\
\end{array}$ & $\begin{array}{c}\text { Cultura } \\
\text { Empreendedora } \\
\end{array}$ & $\begin{array}{c}\text { Instituições } \\
\text { Suporte } \\
\end{array}$ & $\begin{array}{l}\text { Recursos } \\
\text { Humanos } \\
\end{array}$ & Mercados \\
\hline Moda & 1 & 5 & 1 & 3 & 4 & 6 \\
\hline $\begin{array}{l}\text { Desvio padrão } \\
\text { Confiança }\end{array}$ & 1,43 & 1,55 & 1,79 & 1,22 & 1,32 & 1,77 \\
\hline$(95,0 \%)$ & 0,73 & 0,79 & 0,92 & 0,62 & 0,68 & 0,91 \\
\hline
\end{tabular}

Fonte: dados da pesquisa 
$\mathrm{Na}$ opinião dos entrevistados, os dois domínios que necessitam ser priorizados são aqueles vinculados à formulação de políticas públicas e às ações focadas no desenvolvimento de uma cultura empreendedora efetiva. A priorização de tais domínios, mais uma vez, encontra respaldo na pesquisa ICE, que aponta esses dois domínios como aqueles que apresentam pior desempenho de Porto Alegre, em comparação com outras capitais brasileiras.

Em seguida, na opinião dos especialistas, devem ser priorizados, nessa ordem: o fortalecimento das instituições de suporte à atividade empreendedora; o fomento ao desenvolvimento, qualificação e ampliação da oferta de recursos humanos; o desenvolvimento de uma estrutura financeira que dê suporte às iniciativas empreendedoras; e, por fim, a consolidação da organização de mercados, entendido como os mecanismos de interação entre firmas e seus consumidores.

\section{1) OPINIÕES DOS ESPECIALISTAS}

Esta seção está baseada nas opiniões livres, apresentadas pelos dezesseis entrevistados. As ações indicadas no instrumento de coleta de dados foram debatidas e aprofundadas, e os resultados são expostos a seguir:

Políticas Públicas - A tributação é uma temática relevante para as empresas e para o desenvolvimento das cidades. O principal imposto é o ISS (Impostos sobre Serviços), tendo como fato gerador do cálculo o faturamento. Mesmo em situação de prejuízo, a empresa deve pagar. Soma-se a isso a guerra fiscal entre as cidades e Estados, tendo levado à saída de empresas de setores estratégicos, como o da tecnologia, para outros municípios, em função das políticas de alíquotas mais atrativas. Os novos empreendimentos também não têm carência e/ou subsídios. Sendo a legislação de competência federal, o município só pode agir sobre o valor das alíquotas.

Embora a política de recuperação de dívidas das empresas, por vezes, seja percebida como uma forma de privilegiar o mau pagador, em verdade é uma forma de reconhecimento de que o Estado deve apoiar o ato de empreender, no qual concorrem riscos de toda ordem. Tem-se, ainda, um forte componente cultural que não aprecia dar uma nova oportunidade ao empreendedor-devedor, desconsiderando o duro, mas relevante, aprendizado de um fracasso. Neste sentido, é auspiciosa a orientação também da nova proposta do Programa de Microcrédito do Estado, que estará criando uma linha de crédito para saneamento financeiro, procurando levar em conta o impacto da conjuntura nos empreendimentos.

O tema da redução do tempo de abertura das empresas faz parte de um processo mais amplo que é o excesso de burocracia presente na gestão pública brasileira. Segundo o Relatório ICE2017, publicado pela Endeavor, o Brasil figura entre os 15 piores países do mundo, em termos de tempo de tramitação para abrir novos negócios. No Estado do Rio Grande do Sul, em um significativo número de municípios, implantou-se o Projeto da Rede Nacional para a Simplificação do Registro e da Legalização de Empresas e Negócios - REDESIM, instituída em 2007 pelo Governo Federal, segundo a Lei $\mathrm{n}^{\circ} 11.598$, que visa acelerar a abertura de novos empreendimentos através de unificação e simplificação da burocracia. Há casos em que, em 48 horas, consegue-se sair com toda a empresa registrada de ponta a ponta da Junta Comercial até o seu Alvará de Funcionamento. Porto Alegre mantém na referida pesquisa a última colocação dentre os municípios abrangidos, em função da complexidade do processo e da lentidão na implantação do Projeto Simplificar. Dentro do projeto, inclui-se a instalação da denominada Sala do Empreendedor, onde estarão integrados todos os órgãos relacionados com o processo de abertura de novos negócios.

O Programa Fornecedor, uma política de governo que dá preferência às compras das pequenas empresas no setor público, embora bem-intencionado, não surte os efeitos pretendidos, seja pela falta de recursos públicos para sua viabilização, seja pela reduzida abrangência em termos de categoria de produtos/serviços, ou pela própria falta de estrutura dos empreendimentos para atender às demandas que lhe são oferecidas.

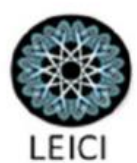


Estimular a geração, a atração e a instalação de novas empresas é uma política pública de cunho estratégico. Para crescer, uma cidade precisa desenvolver não apenas condições sociais atraentes, mas também uma atividade econômica robusta e recorrente (KOTLER, 2005). O Entrevistado 2 (E2) faz um alerta, esclarecendo que: (...) as políticas públicas de instalação de empresas deviam ser políticas públicas não só de incentivos, de manutenção, mas de como essas empresas se comprometem com o desenvolvimento das cadeias porque você tem que trabalhar para os habitats. (...) a GM foi criticada mas conseguiu desenvolver uma cadeia de fornecedores de pequenos negócios e mobilizou a economia. (...) Este é um bom exemplo da materialização do entendimento de que as cidades têm para alavancar a sua vida econômica, que atrair e estimular negócios não apenas com o aporte das pequenas e médias empresas, como também das grandes corporações nacionais e internacionais (KOTLER, 2005). Nesse sentido, Porto Alegre necessita rever a estratégia adotada de desindustrialização, cujas motivações são questionáveis pelos efeitos de empobrecimento da economia local.

Mercado de Finanças - Para suportar o surgimento e o desenvolvimento dos atuais e dos novos negócios, precisa-se dispor de recursos para investimento, e isto é verdadeiro para todos os setores e porte dos empreendimentos. Conforme registra o Entrevistado 5:

"Joseph Schumpeter, já na década de 50 dizia (...) em se tratando do desenvolvimento da inovação tecnológica, que o outro lado da inovação era o crédito, e que deveriam ser criados mecanismos inovadores também para este, atendendo às especificidades de um empreendimento que oriente pela inovação. No Brasil (...) o financiamento não supera a fase de desenvolvimento, para alcançar o 'salto mortal' que é assumir o risco de viabilidade do mercado" (E5).

Parece estranho que o relatório ICE-2017 aponte Porto Alegre como a segunda colocada em acesso das empresas ao capital. Esta situação de facilidade não tem sido confirmada na presente pesquisa. Dentre às alternativas, em nível local, há o financiamento via Fundos Públicos. No que diz respeito aos novos negócios de base tecnológica, os investidores-anjo e as aceleradoras têm cumprido um papel fundamental, como impulsionadoras desses empreendimentos.

Em relação aos micro e pequenos empreendimentos, uma das fontes de financiamento é o Programa de Microcrédito. Sendo público, o mesmo fica dependente da disponibilidade de recursos que, em uma crise como a atual, gera a sua descontinuidade. Além disso, o Programa Gaúcho de Microcrédito está em fase de transformação, deixando claro que não se constituirá em um programa de distribuição de recursos, senão que será voltado para a capacitação de gestão, a melhoria dos processos e dos produtos; enfim, ao desenvolvimento dos negócios, de forma geral.

Cultura empresarial - À semelhança do relatório do ICE-2017, a presente pesquisa indicou a cultura empreendedora como uma das fragilidades da Capital. A partir desta constatação procurou-se encontrar as causas. A falta de investimentos em iniciativas de educação empreendedora, promovidas pelas instituições de ensino ao longo do percurso formativo. Nas de ensino superior, especialmente as que implementaram os seus parques tecnológicos, incubadoras, centros de empreendedorismo etc. Verificam-se iniciativas importantes para disseminar e materializar os efeitos de uma cultura empreendedora: (...) o Programa Talentos que visa estimular desde a idade escolar o empreendedorismo e o Núcleo de Empreendedorismo que (...) oferece três disciplinas transversais em todos os cursos de graduação. Constituem-se em ilhas de excelência, não chegando a impactar na cultura da sociedade com relação ao empreendedorismo. Além disso, pouco se fala de empreendedorismo e das lideranças empresariais que não são valorizadas e reconhecidas pela sua trajetória.

No que diz respeito à questão estrutural, Porto Alegre e o RS encontram-se em uma situação econômica e financeira alarmantes. O processo de formação de lideranças é um aspecto que tem sido

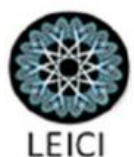


negligenciado pelas instituições de ensino e pesquisa, que têm precipuamente essa missão. Contribui, ainda, para aprofundar este quadro, acirrando os conflitos e precarizando as relações de coesão entre as instituições e, entre as pessoas, a baixa intensidade de interação e comunicação entre estas organizações.

Instituições de suporte - Percebe-se que a estrutura do ecossistema em Porto Alegre existe, porém, ainda há pouca conexão entre os atores. Existe pouco diálogo entre as agências, não havendo uma agenda articulada de atividades. Um bom exemplo de coesão institucional é o da cidade de São Leopoldo (Região Metropolitana de Porto Alegre), através da governança (modelo Tríple Hélice) do Parque Tecnológico da Universidade do Rio dos Sinos (Unisinos). Em Porto Alegre, houve o caso da criação do Fórum de Ensino Superior, o qual foi criado há três anos. Quando ficou claro que o governo municipal não ia aportar financiamento público, além do esforço de coordenação, ocorreu a desarticulação do movimento. Há dificuldade de encontrar instituições para liderar e para integrar às iniciativas que são desenvolvidas na cidade. Fica claro que, da mesma forma que se percebe uma baixa cultura empreendedora, o mesmo ocorre com a cultura associativa.

Recursos Humanos - Se, por um lado, Porto Alegre e o Rio Grande do Sul têm a melhor estrutura universitária do país, percebe-se, por outro lado, dificuldades de diferentes ordens, a saber: tanto na retenção quanto na atração de talentos para o Brasil; na orientação dos currículos dos cursos que exigem atualizações nos conteúdos e nas metodologias de ensino; no viés da pesquisa que, mesmo apresentando reconhecida qualidade, por vezes, a ênfase da avaliação está mais na elaboração de artigos científicos do que no desenvolvimento de negócios e tecnologias capazes de gerarem impactos na renda, no emprego e nos tributos. Os aspectos comportamentais também são determinantes no desempenho empreendedor. Dentre as carências técnicas, chama a atenção à ausência de domínio de outros idiomas, em especial o inglês, constituindo-se num fator limitante para desenvolver um diálogo internacional. O perfil educacional dos empreendedores reflete os problemas históricos da educação no Brasil.

Mercados - A existência de mercados é essencial para o desenvolvimento e para a atração de empresas às cidades, promovendo prosperidade - traduzido em riqueza - empregos e qualidade de vida à população. A propensão de abertura de novos negócios em uma cidade se relaciona com vários aspectos, a saber: poder de compra da população residente, infraestrutura, capital humano disponível, ambiente regulatório favorável, cultura local, interesse de governantes e de políticos etc.

Por meio da pesquisa, solicitou-se aos entrevistados que avaliassem alguns setores que entendessem possui potencial econômico para o seu desenvolvimento na cidade de Porto Alegre. Além de ser confirmada a maioria das proposições, foram indicados alguns nichos de negócios nos mercados indicados como noutros que estão emergindo com possibilidades de se afirmar e de se consolidar em um perfil econômico para a cidade.

Por ser Porto Alegre uma capital voltada ao setor de serviços, uma das possibilidades levantadas pelos entrevistados diz respeito à constituição de uma rede de empresas (ex. Tradings) ou de uma Zona Franca para o desenvolvimento de atividades de comércio exterior. Em função da orientação e da complexidade da legislação de comércio exterior, torna-se difícil definir uma cidade para centralizar negócios desta natureza. O Brasil é o maior armazém do mundo. O maior produtor de grãos, o maior produtor de proteínas do mundo. (E 16). Soma-se a isso que (...) estamos na iminência de abrir o acordo com a União Europeia. É um acordo que vai facilitar, ajudar a nossa agroindústria, principalmente à pecuária, (...) mas vai impactar fortemente os produtos manufaturados, porque o europeu vai entrar aqui (E14).

Em relação à pequena empresa, considera-se que, sendo o mercado brasileiro tão grande e o mercado externo tão complexo, em função das exigências burocráticas e das necessidades de capital, torna-se desinteressante operar nesse mercado. Mostra disso é que (...) apenas $2 \%$ das pequenas empresas conseguiram exportar e que se bem o incentivo ao mercado externo abre uma porta

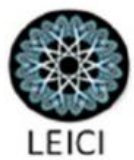


importante, mas tem que se ter muito cuidado para não levar à empresa ao buraco (E1). Para a grande empresa, às vezes, o mercado externo é uma alternativa, "porém, uma empresa só vai para fora quando está difícil aqui dentro" (E16).

O setor de saúde apresenta infraestrutura e potencial de desenvolvimento para diversos tipos de negócios. Em relação aos hospitais, Porto Alegre tem a melhor rede hospitalar do Brasil, alguns deles certificados internacionalmente, o que tem incentivado a avançar na implementação de prestação de serviços nas diversas especialidades à população local e à estrangeira (E2). Aí temos "um foco para desenvolvimento de uma grande indústria de engenharia biomédica, porque falta tudo nessa área (...)” (E3). Está-se pensando também em um Centro de Telemedicina. (E11). Criou-se o Curso de Engenharia Biomédica oferecido pela Unisinos, o qual foi pioneiro no Brasil, vindo a suprir a eventual demanda de profissional nessa área. Também, "dispomos de grande potencial para o desenvolvimento da indústria de biofármacos (...)" (E5).

Se há um segmento que divide opiniões quanto ao seu potencial, esse segmento é o turismo. Embora seja um dos setores que mais cresce no mundo, Porto Alegre, mesmo tendo sido indicada como a capital cultural do Mercosul, contando com diferentes etnias européias, principalmente alemã e italiana, e uma infraestrutura adequada e reconhecida como a terceira cidade do Brasil para sediar grandes eventos, depois de São Paulo e do Rio de Janeiro, ainda não se posiciona como um destino turístico relevante. Em consequência disso, alguns entrevistados reafirmaram essa condição, enquanto outros se aventuraram a identificar o que deve ser corrigido para que Porto Alegre realize a sua vocação turística.

$\mathrm{Na}$ avaliação feita por vários entrevistados, a cidade deu as costas ao seu principal atrativo natural - o Lago Guaíba - que, de tão extenso, é chamado de Rio Guaíba. À semelhança de outros países, investiu-se na revitalização do porto da cidade, com o potencial de gerar negócios inovadores, especialmente vinculados ao esporte e ao lazer, somado ao patrimônio cultural do Centro Histórico da cidade. Há, ainda, uma qualificada infraestrutura hoteleira e gastronômica. Em relação aos espaços culturais, existem problemas pela falta de investimentos e de divulgação, gerando descontinuidade das atividades. Soma-se a isso a falta de um grande centro de eventos público, o que também restringe uma das poucas atividades com possibilidades reais de desenvolvimento que é o turismo de eventos.

O Estado se constitui no segundo polo de microeletrônica do país. No Rio Grande do Sul, temos quinze parques tecnológicos. Em Porto Alegre, destacamos o Tecnopuc, vinculado à Pontifícia Universidade Católica (E13), que está participando do projeto do $4^{\circ}$. Distrito em Porto Alegre, uma região deprimida, em que se estão aproveitando as estruturas imobiliárias para abrigar empreendimentos inovadores no segmento da economia criativa, incluindo negócios de produção audiovisual, de moda, de cerveja artesanal etc. Os parques tecnológicos têm ajudado a sensibilizar para que a pesquisa acadêmica tenha aplicabilidade (E2). A Universidade é essencial para gerar patentes e inovação, superando a condição de um empreendedorismo pouquíssimo inovador (...) (E15). Por último, indicou-se o setor de tecnologias sustentáveis (eólica e solar) com bom potencial para desenvolver.

\section{5) CONSIDERAÇÕES FINAIS}

Como restou desenvolvido ao longo deste texto, existem, ao mesmo tempo, aspectos que potencializam e que permitem ambicionar uma melhor posição do ecossistema empreendedor de Porto Alegre, e diversos pontos considerados precários e de difícil transformação, sem um compromisso explícito do governo, da sociedade e de cada um dos componentes do sistema.

A ausência marcante de lideranças políticas, empresariais e sociais qualificadas e comprometidas com os destinos da cidade é um dado crítico e de difícil superação, e que surge de modo preponderante nas falas dos entrevistados. As instituições, especialmente as universidades e os partidos políticos, têm negligenciado essa missão. Ao longo da história, o Rio Grande do Sul foi

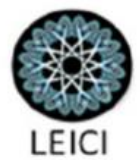


pródigo na formação de lideranças voltadas para os campos político e militar, e pouco para o segmento empresarial. Na opinião de muitos dos entrevistados, há necessidade de se fortalecer o papel de uma liderança empresarial ativamente comprometida com o desenvolvimento do ecossistema inovador de Porto Alegre.

O meio empresarial gaúcho parece não se afinar muito com a possibilidade de dar a sua contribuição no setor público, especialmente aportando a sua experiência de gestão. É bem possível que isso decorra da forma como se concebe a inserção dos futuros dirigentes na vida pública, controlada pelos caciques dos partidos políticos que ambicionam, a partir da sua eleição nas casas legislativas, ingressar ao executivo, na maior das vezes sem experiência na vida empresarial.

Também, é importante registrar um aspecto que envolve todas as relações institucionais, qual seja a cultura pouco cooperativa e beligerante, democrático às avessas e imediatista da população do Rio Grande do Sul e por decorrência do porto-alegrense. Por vezes, avaliando a história do Rio Grande do Sul, fica evidente que a defesa de interesses pessoais ou de um grupo, sobressai aos interesses da cidade. Neste cenário, promover um trabalho em rede, que conte com a participação de diversas instituições, resta cada vez mais impossibilitado. E, como se sabe, um dos fatores relevantes ao ecossistema empreendedor é a formação de um forte suporte de capital social.

O imediatismo é outra característica presente neste caldo de cultura. Como planejar uma cidade, como superar os gargalos que não são poucos e tão complexos, esperando que a transformação se dê num passe de mágica. O processo político eleitoral traz consigo este viés cultural. Existem quatro anos para se fazer algo que tenha o seu impacto junto ao eleitorado, para conquistar a sua reeleição. Tomam-se decisões estratégicas, como no caso mais marcante da economia de Porto Alegre, que é o processo de desindustrialização, sem levar em conta as consequências. Em algum momento, a conta desse processo chega, e inevitavelmente, quem paga é a população da cidade.

\section{6) REFERÊNCIAS BIBLIOGRÁFICAS}

Adner, R. Kapoor, R. (2010). Value creation in innovation ecosystems: How the structure of technological independent affect firm performance. IN: New technology generations, Strategy management journal, 31(3): 306-333.

Albagli, S., \& Maciel, M. L. (2003). Capital social e desenvolvimento local. Pequena empresa: cooperação e desenvolvimento local. Rio de Janeiro: Relume Dumará, 423-440.

Amaral Filho, J. D. (2002). É negócio ser pequeno, mas em grupo. Desenvolvimento em debate. Rio de Janeiro: Banco Nacional de Desenvolvimento Econômico e Social: Mauad, 3, 85-118.

Arruda, C. et al. (2013). Causa da Mortalidade de Startups Brasileiras: O que fazer para aumentar as chances de sobrevivência no mercado?. Fundação Dom Cabral.

Cassiolato, J. E., \& Szapiro, M. (2002). Arranjos e sistemas produtivos e inovativos locais no Brasil. Notas técnicas da fase II do Projeto "Proposição de políticas para a promoção de sistemas produtivos e inovativos locais de micro, pequenas e médias empresas brasileiras.

Cohen, B. (2006). Sustainable Valley Entrepreneurial Ecosystem. Business Strategy and the Environment. v. 15, n. 1, p. 1-14.

Costa, Achyles B. \& Costa, Beatriz M (2005). Cooperação e Capital Social em Arranjos Produtivos Locais. In: XXXIII Encontro Nacional de Economia (ANPEC), Natal-RN.

Freeman, C.(1995). The national system of innovation in historical perspective. Cambridge Journal of Economics, v. 19, n. 1, pp. 5-24.

Isenberg, D. (2010). How to Start an Entrepreneurial Revolution. Harvard Business Review. Retrieved June 2010. https://hbr.org/2010/06/the-big-idea-how-to-start-an-entrepreneurialrevolution/ar/1

Kotler, P. (2015). Conquistando mercados mundiais: como as empresas investem e prosperam na cidades dinâmicas do mundo. Rio de Janeiro, RJ: Alta Books 
Krugman, P. (1991). Geography and Trade. Cambridge (Mass.): MIT-Press.

Lastres, H. M., Cassiolato, J. E., Lemos, C., Maldonado, J., \& Vargas, M. A. (1999). Globalização e inovação localizada. Nota técnica, $1,98$.

Lundvall, B.A. (1992). National Systems of Innovation: towards a theory of innovation and interactive learning. Pinter, London

Mason, C.; Brown, R. (2013). Entrepreneurial ecosystems and growth oriented entrepreneurship. Background paper prepared for the workshop organised by the OECD LEED Programme and the Dutch Ministry of Economic Affairs on Entrepreneurial Ecosystems and Growth Oriented Entrepreneurship, The Hague, Netherlands.

Moore, J. (2006). Business ecosystems and the view from the firm. The Antitrust Bulletin. 51, 1 (Spring): 31

Nadgrodkiewicz, A. (2013). Building Entrepreneurship Ecosystems. Global Programs Center for International Private Enterprise.

Porter, M. (1998). Clusters and the New Economics of Competition. Harvard Business Review, November-December 1998.

Portes, A. (2000). Capital social: origens e aplicações na sociologia contemporânea. Sociologia, Problemas e práticas, v. 33, p. 133-158.

REDESIST (2005). Glossário sobre arranjos e sistemas produtivos e inovativos locais. Rio de Janeiro.

Stam, E. (2015). Entrepreneurial Ecosystems and Regional Policy: A Sympathetic Critique. Discussion Paper Series. Utrecht School of Economics / Tjalling C. Koopmans Research Institute.

Venkatraman, N. (2004). Strategic Orientation of Business Enterprises: The Construct, Dimensionality, and Measurement. Management Science, v.35, n. 8, p. 942-962. 